\title{
Note on the measurement of the double sulphates of zinc and soda, and of magnesia and soda
}

\author{
Prof. W.H. Miller
}

To cite this article: Prof. W.H. Miller (1847) Note on the measurement of the double sulphates of zinc and soda, and of magnesia and soda, Philosophical Magazine Series 3, 31:211, 540-541, DOI: $10.1080 / 14786444708645905$

To link to this article: http://dx.doi.org/10.1080/14786444708645905

曲 Published online: 30 Apr 2009.

Submit your article to this journal $₫$

Џll Article views: 2

Q View related articles $\sqsubset$ 
intimate mixture with the oil, and exposing it in a state of perfect division to the oxygen of the air. Lastly, M. Therault is of opinion that oil of valerian is not a substance of a complex nature, and that it may be entirely converted into valerianic acid.

This conversion is readily explained. According to Ettling, the formula of valerianic acid is $\mathrm{C}^{20} \mathrm{H}^{18} \mathrm{O}^{3}+\mathrm{H}^{2} \mathrm{O}$; if that of oil of valerian be $\mathrm{C}^{20} \mathrm{H}^{20} \mathrm{O}^{2}$, and if two atoms of oxygen be made to intervene, one of which combines with two atoms of hydrogen to form water, and the other be added, we shall have the following equation :

$$
\mathrm{C}^{20} \mathrm{H}^{20} \mathrm{O}^{2}+2 \mathrm{O}=\mathrm{C}^{20} \mathrm{H}^{18} \mathrm{O}^{9}+\mathrm{H}^{2} \mathrm{O} \text {. }
$$

M. Therault finishes his memoir with observing, that the process for extracting valerianic acid, proposed by Messrs. Smith of Edinburgh in the Journal de Pharmacie for January last, appears to be a good one; excepting that he would propose to use a caustic instead of a carbonated alkali, and after having boiled the mixture, to expose it for a month to the air, stirring it several times a day; not to subject the residue to pressure, and to distil with the roots, which greatly facilitate the operation. When afterwards the distilled liquor has been saturated by means of an alkali, and the valerianate of potash or soda has been concentrated, it is essential not to employ an excess of sulphuric acid to separate the valerianic acid; it would be better to leave a small portion of the valerianate undecomposed, for towards the end of the distillation, the organic matter mixed with the salt is carbonized and sulphurous acid is formed, which appears to react upon the valerianic acid.-Journ. de Pharm. et de Ch., Septembre 1847 .

NOTE ON THE MEASUREMENT OF THE DOUBLE SULPHATES OF ZINC AND SODA, AND OF MAGNESIA AND SODA. BY PROF. W. H. MILLER.

The crystals were not good enough for me to obtain a very satisfactory result from a few observations; they are however sufficiently good to show that they are isomorphous.

The crystals belong to the oblique prismatic system.

The angles between normals to the faces are-for the oxide of zinc salt,

$$
\begin{array}{rrr}
n n^{\prime} & 113^{\circ} & 4 \\
u u^{\prime} & 74^{\circ} & 12
\end{array}
$$

the angle between a normal to $c$ and the intersection of

$$
\begin{aligned}
& u, u^{\prime}=10^{\circ} 22^{\prime} \\
& u c \quad 83^{\circ} 46^{\prime} \\
& r c \quad 49^{\circ} 54^{\prime}
\end{aligned}
$$

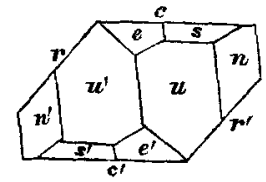

The symbols of the simple forms, in the notation which I use, are-

$$
\begin{aligned}
& \text { c 001, r 101, n 110, } \\
& u 120, e 011, s 121 \text {. }
\end{aligned}
$$

The faces of the magnesian salt are more irregular than those of the former, so that I cannot pretend to determine the difference between the angles of these crystals. 
The angles given above must be considered as rough approximations only. In a little time perhaps I may be able to obtain more accurate values of them.-From the Proceedings of the Chemical Society, vol. iii. p. 391 .

\section{NATIYE CARBONATE OF NICKEL.}

'This new mineral was exhibited last year at the Philosophical Society's exhibition in Glasgow, and was examined at the time, at the request of Dr. R. D. Thomson, by his pupil Mr. John Brown, in the College Laboratory. It occurs in the form of thin green cry. stalline layers, on the surface of chrome iron ore from America. It dissolves with effervescence in dilute hydrochloric acid. The solution is precipitated black by sulphohydret of ammonia; is precipitated and dissolved in excess by caustic ammonia, yielding a characteristic coloured solution. Caustic soda precipitates the solution green, without resolution. It is accompanied, apparently in union, by carbonates of lime and magnesia-isomorphous bodies. The fact of its occurring on the surface of chrome iron, and having been mis. taken for sesquioxide of chrome, renders it probable that oxide of nickel may exist in that mineral occasionally.-R. D. ' $T$.

\section{AN EXAMINATION AND ANALYSIS OF THE "NADELERZ," OR NEEDLE ORE OF BISMUTH. BY. E. J. CHAPMAN, ISQ.}

THE "needle ore" occurs in thin prismatic crystals, generally forming more or less radiated groups imbedded in quartz, at Ekatherinenburg in Siberia, the only known locality in which it has been hitherto found. The crystals are too imperfect to admit of measurement; but they appear to belong to the Trimetric or Prismatic system, and to have for the primary form a right rectangular prism, or perhaps more correctly a right rhombic one, in which the angle MM closely approaches a right angle.

The colour of this mineral is dark steel-gray on the fractured surface, but externally the true colour is usually masked by a yellow tarnish. The powder or "streak" is black; the degree of hardness $2 \cdot 0$ to $2 \cdot 5$, or between that of rock-salt and calc-spar; and the specific gravity about $6 \cdot 1$.

Before the blowpipe it fuses instantly and may be almost entirely volatilized, forming a yellow incrustation of the mingled oxides of lead and bismuth on the support. The presence of bismuth and copper may be ascertained by fusion with "microcosmic salt" and a little tin on charcoal in the reducing flame, when the lead, which is clear whilst hot, becomes on cooling of a grayish-black colour with red patches. With carbonate of soda on charcoal in the same flame, it forms an alkaline sulphuret. The lead is best detected by boiling a fragment in nitric acid, filtering, dissolving the residue (sulphate of lead) in caustic potash, dilutiug the solution, and reprecipitating by sulphuric acid.

This ore was first described by Karsten and analysed by John; and although a considerable period has elapsed since the date of this analysis, yet, probably from the rarity of the mineral, its composition 